\title{
Film Horor Sebuah Definisi yang Berubah
}

\author{
M. Yoesoef
}

ABSTRACT Horror film is a film genre that presents things that are frightening, tense, and horrifying. The idea of horror film is basically to terrorize the audience through various terrifying acts or actors. Horror films in the beginning are closely related to stories rooted in the culture of Europe, especially English literature. The definition of horror in the beginning was a story that presented uncomfortable feelings to the readers. This definition changed with the development of film. Horror film developed into a genre that came to stand side by side with drama film, comedy film, gangster film, and action film.

Kata KunCI Film horor, definisi horor, genre film.

Film sebagai sebuah konsep hiburan dimulai sejak awal abad ke-20 di Amerika dan kemudian menjadi sebuah industri kebudayaan massa (mass culture) yang sangat berpengaruh terhadap konsep hiburan lainnya. Pada awal pertumbuhannya, film dibuat orang untuk mendokumentasikan peristiwa penting seperti halnya fotografi. Teknologi film pada masa itu merupakan revolusi fotografi yang fenomenal melalui penemuan teknologi gambar hidup. Sejak saat itu penyempurnaan gambar hidup terus dilakukan, sampai akhirnya berdirilah perusahaan-perusahaan film yang bertujuan menjadikan film sebagai komoditas dalam industri hiburan. Keberhasilan film sebagai komoditas mendapat dukungan masyarakat kota yang semakin mengukuhkan gaya dan irama hidupnya sebagai masyarakat baru yang memerlukan sesuatu yang berbeda dari kemonotonan kehidupan sehari-hari mereka.

Selain film dokumenter, pada paruh kedua masa pertumbuhan perfilman, dibuatlah film yang memiliki alur cerita. Kehadiran cerita dalam film pada perkembangannya memunculkan genre film, yaitu film dokumenter, drama, gangster, dan horor. Genre film dokumenter pada intinya menampilkan peristiwa-peristiwa penting dalam kehidupan dan sejarah manusia; film drama adalah film yang menyuguhkan kisah manusia yang dramatik; film gangster menyuguhkan berbagai tokoh dan kehidupan kalangan gangster; sementara film horor menyuguhkan ketakutan dan kengerian sebagai menunya.

Saat ini, genre film tidak terbatas pada tiga genre tersebut. Sekarang ini dikenal film animasi yang mempunyai perkembangan sendiri; film suspence 
yang mengeksploitasi perasaan tegang yang kemudian dikenal dengan thriller; dan film fiksi ilmiah (science fiction) yang mengeksplorasi penemuanpenemuan baru atau yang berlatar waktu masa yang akan datang.

Beragamnya genre film tersebut menunjukkan betapa berhasilnya film sebagai alat hiburan yang telah memesona masyarakat kota dan desa bahkan para pembuat film itu sendiri seiring dengan perkembangan zaman. Pada perkembangan sepuluh atau dua puluh tahun terakhir telah lahir pula film-film berteknologi tinggi, yang memanfaatkan kecanggihan perangkat lunak komputer, multimedia, dan digital. Dengan dukungan teknologi yang canggih itu, semakin luas pencapaian kreativitas manusia melalui film. Formula bahwa film menyuguhkan "dunia" yang berbeda sejalan dengan konsep membawa mimpi ke tengah realita hidup manusia. Oleh karena itu, kehadiran film sebagai industri hiburan justru menguatkan pandangan bahwa perusahaan-perusahaan film dalam industri ini adalah "pabrik impian" (dream factory). ${ }^{1}$

Daya tarik utama film adalah pada cerita, pemeran, sutradara, kemudian baru unsur teknologi yang digunakan di dalamnya. Tiga hal pertama (cerita, pemeran, dan sutradara) pada kenyataannya dapat bertukar tempat kepopulerannya sesuai dengan tren yang berlaku pada masanya. Bahkan kehadiran pemeran tertentu atau sutradara tertentu dapat mengalahkan unsur cerita. Artinya, masyarakat tidak peduli dengan unsur ceritanya tetapi lebih memperhatikan para pemerannya atau sutradaranya. Dalam hal ini, seringkali kehadiran pemeran tertentu dalam film menjadi penanda bermutunya film itu, demikian juga dengan nama sutradara tertentu berkaitan langsung dengan mutu hasil kreativitasnya.

Apabila memperhatikan unsur cerita yang ada di dalam film, kita akan menemukan sejumlah tipologi cerita film yang sesuai dengan genrenya. Tulisan ini secara umum mengemukakan perkembangan film horor sejak kemunculannya hingga sekarang dan secara khusus mendeskripsikan sejumlah unsur yang terdapat dalam film horor.

Hal menarik yang berkaitan dengan film horor adalah pertama, bahwa sejak awal dibuatnya film horor sampai sekarang ini terlihat adanya perubahan definisi mengenai horor; kedua, adanya kecenderungan eksploitasi rasa ketakutan dan kengerian dalam film horor dari waktu ke waktu semakin beragam; ketiga, kuat kecenderungannya film horor mengeksplorasi (dan mengekspoitasi) hal-hal yang berkaitan dengan kepercayaan dan kemustahilan mengenai sesuatu. Eksplorasi dan eksploitasi itu bermuara pada upaya menghibur sekaligus menyerap keingintahuan masyarakat.

Dengan demikian, soal yang mencuat dari hal-hal di atas adalah (1) perubahan apa saja yang terjadi dalam film horor. Perubahan itu tentu didukung oleh suatu pemahaman (definisi) mengenai film horor yang terus

\footnotetext{
1 Umar Kayam, "Film sebagai Sarana Hiburan dan Ekspresi Dramatik," dalam Seni Tradisi Masyarakat. (1981), h.136.
} 
berkembang. Perubahan definisi ini tentu sangat berkaitan dengan perkembangan pola pemikiran masyarakat yang ditangkap oleh para sineas; (2) konsep yang berubah itu tentu akan mengubah struktur cerita-oleh karena itu, pada bagian mana saja perubahan itu terjadi; dan (3) kecenderungan membuat film horor tidak saja terjadi di luar negeri, tetapi juga di Indonesia. Hal ini memunculkan satu pertanyaan mendasar, yaitu bagaimana konsep film horor yang dibuat Indonesia dan ke arah mana kecenderungan film-film horor di Indonesia itu?

\section{DEFINISI FILM HOROR}

Film adalah salah satu kitsch yang dijajakan sebagai barang komoditas. Film dikemas dalam berbagai konsép sehingga memunculkan genre-genre film. Kita mengenal sejumlah genre film, seperti film koboi, film laga, film komedi, film animasi (kartun), film horor, film fiksi ilmiah, film thriller, dan film drama.

Film horor adalah genre film yang menyuguhkan hal-hal yang menakutkan, menegangkan, dan mengerikan. Konsep film horor pada dasarnya adalah meneror penonton melalui berbagai adegan dan atau tokoh yang menakutkan. Pada bagian ini akan diuraikan apa dan bagaimana definisi dan konsep film horor serta bagaimana perubahan definisi dan konsep film ini sejak awal pembuatannya hingga sekarang. Pada bagian ini juga akan dijelaskan kecenderungan tematik sejalan dengan pelbagai perubahan itu.

Film horor dikukuhkan sebagai salah satu genre film oleh Hollywood pada awal tahun 1930-an. Masuknya cerita horor ke dalam film sebenarnya mempunyai sejarah yang panjang, antara lain adanya pengaruh dari ceritacerita atau mitos-mitos yang hidup di masyarakat Eropa. Film-film horor pada awal mulanya tidak bisa dilepaskan dari cerita yang berakar pada kebudayaan Eropa, khususnya kesusastraan:Inggris. Dua mitos utama yang lekat dengan cerita horor adalah Frankenstein ${ }^{2}$ dan Dracula ${ }^{3}$ yang bermula dari novel yang dipublikasikan pada abad ke-19. Satu lagi karya yang penting dalam cerita horor adalah karya Polidori yang berjudul The Vampire yang dipublikasikan pada tahun 1819. Cerita-cerita horor tersebut oleh Pirie, seorang pemerhati cerita horor, digolongkan ke dalam jenis horor gotik yang menandai sumbangan kesusastraan Inggris pada genre horor. Di Inggris sendiri produksi film horor yang mengacu pada tradisi gotik yang berakar pada tradisi kesusastraan Inggris pada abad ke-18-itu baru dimulai pada akhir tahun 1950-an.

Cerita-cerita dalam film horor (juga dalam bentuk novel) pada awal pemunculannya umumnya menggambarkan kehidupan masyarakat yang diganggu oleh monster. Monster ini melakukan tindak pembunuhan dan penganiayaan. Tindakan ini sangat mengancam masyarakat dalam bentuk pembunuhan dengan cara-cara yang tidak lazim dan cenderung bersifat

\footnotetext{
${ }^{2}$ Frankenstein karya Mary Shelley dipublikasikan pada tahun 1818.

${ }^{3}$ Dracula karya Bram Stocker dipublikasikan pada tahun 1897.
} 
supernatural sesuai dengan karakteristik dari si pelaku itu sendiri (monster). Sensasi yang tak lazim itu dijadikan suatu nilai lebih oleh para pembuat film horor di Hollywood yang di kemudian hari dijadikan sebuah formula dalam pembuatan film horor.

Noel Carroll (1990) dalam bukunya Philosophy of Horror: Paradoxes of the Heart ${ }^{4}$ mengemukakan dua tipe film horor, yaitu art-horror dan horror. ${ }^{5}$ Yang termasuk ke dalam art-horror adalah semua jenis fiksi yang menampilkan unsur supernatural dalam narasinya, termasuk di dalamnya adalah horor psikologis dan fiksi ilmiah. Dan yang tergolong pada tipe horror adalah film-film yang menampilkan monster, hantu, sesuatu yang aneh dan muncul tiba-tiba, dan alam kematian. Perumusan film horor ke dalam dua tipe umum ini pada perkembangannya tidak memuaskan, karena dinamika cerita horor dari tahun ke tahun semakin kompleks. Hal itu menyebabkan pula terjadinya perubahan pada definisi horor.

Definisi film horor sebenarnya dapat dinyatakan sebagai sebuah genre yang di dalamnya menampilkan sesuatu yang diinterpretasikan sebagai ketidaknyamanan dan gangguan pada perasaan dan hal itu membutuhkan pembebasan. ${ }^{6}$ Dengan kata lain, kata kunci untuk film horor adalah 'menakutkan'.

Namun demikian, mendefinisikan film horor dengan mempertanyakan tentang hal-hal apa saja yang termasuk dalam genre ini, bagaimana hal itu dipahami, dan bagaimana hubungannya dengan ide mengenai realisme dan genre yang serupa dengan itu, seperti fiksi ilmiah (science fiction). Cara terbaik untuk mendefinisikan genre ini adalah menggunakan definisi yang terus berubah di dalamnya industri perfilman yang mencoba untuk menjual produknya dan penonton mencoba memahami apa yang mereka konsumsi. Karakter komersil dari sebuah genre juga harus dikenali karena sangat mempengaruhi bagaimana film itu didefinisikan dalam sebuah keadaan sejarah tertentu. Tanpa adanya panduan dalam mendefinisi genre ini maka yang tinggal hanyalah keragü-raguan. Contohnya Jankovich dalam bukunya mengenai film horor Amerika berusaha untuk memisahkan film horor dari film fiksi ilmiah. Namun dia gagal menetapkan apa saja yang termasuk dalam film horor sehingga kedua jenis film itu jadi seperti sama saja, walau perbedaan tetap jelas terlihat. Dia juga gagal menentukan status film "Psycho" yang ambigu itu. Film ini dikategorikan sebagai filith horor, tapi tidak secara jelas dibicarakan mengapa film ini dika tegorikan sebagai film horor. Film ini mungkin dibuat untuk merangsang rasa ketakutan tapi film lainnya pun seperti thrillers, pembunuh misterius, dan film laga juga merangsang rasa takut orang. Jadi di sini, bukan rasa takut yang jadi kuncinya.

\footnotetext{
${ }^{+}$Noel Carroll, The Philosophy of Horror or Paradoxes of the Heart. New York: Routledge, 1990)

${ }^{5}$ Lihat Daniel Shaw, 1997, "A Humean Definition of Horror", dalam "Film Philosophy", Vol.1 No.4, August 1997. <http://www.film-philosophy.com/vol1-1997/n4shaw>

${ }^{6}$ Dominic Strinati. (2000). An Introduction to Studying Popular Culture. London and New York: Routledge, h. 82.
} 
Ada pandangan umum yang telah berkembang bahwa dikatakan film horor apabila di dalamnya ditampilkan sebuah monster atau sesuatu yang bersifat monster. Kehadiran tokoh ini adalah agar suasana horor itu menjadi nyata dan eksplisit, bukan sekadar sesuatu yang dirasakan atau dibersitkan saja. Adanya tokoh serupa itu bisa dijadikan indikasi atau satu acuan dalam mendefinisi mana film horor dan mana yang bukan.

Dahulu banyak film yang intinya berusaha untuk menangkap dan menjelaskan kehadiran mahluk supernatural dengan menggunakan berbagai alat di sebuah rumah tua atau yang mempunyai nilai historis tertentu. Kalau sampai akhir cerita, tidak ada monsternya dan/atau tidak ada perbuatan si monster yang membahayakan seperti membunuh, meneror, dan sebagainya, pastinya film seperti itu tidak bisa dimasukkan ke dalam film horor. Satu hal yang cukup menolong dalam mendefinisikan film horor adalah konsepnya Todorov mengenai film horor.

Todorov melakukan kajian terhadap cerita dan film horor. Ia mengemukakan bahwa ada tiga kecenderungan bentuk dalam film horor, yaitu horor berkaitan dengan hal-hal yang misterius atau aneh (the horroruncanny) yaitu, fenomena yang aneh dan misterius itu dalam cerita dapat dijelaskan oleh hukum-hukum yang berlaku dalam realitas; horor yang mengagumkan (the horror-marvelous), yaitu film horor yang digolongkan dalam bentuk horor yang mengagumkan merupakan kebalikan dari tipe pertama. Pada tipe kedua ini menyuguhkan keirasionalan dan hal tidak dapat dijelaskan, tetapi diterima begitu saja; dan horor yang luar biasa (the horror-fantastic), yaitu film horor yang pada akhir ceritanya mengarahkan pembaca (penonton) ke situasi ragu-ragu, yaitu meragukan tentang hal-hal yang natural dan supernatural atau hal-hal yang nyata dan tidak nyata dalam kehidupan manusia. ${ }^{7}$

Horor yang berkaitan dengan kemisteriusan atau keanehan yang terdapat dalam cerita (film) horor, menurut Todorov, berkaitan dengan akhir cerita yang dipandang tidak biasa, tidak terduga, atau mengejutkan. Kemisteriusan melingkupi akhir cerita yang bisa dijelaskan dengan penjelasan yang rasional, yang dapat diterima akal sehat. Walaupun pada bentuk horor ini, dunia supernatural masih dipandang sebagai dunia yang asing dan menjadi ancaman yang paling menakutkan. Film-film yang tergolong ke dalam tipe ini disebutkan oleh Todorov antara lain Freaks dan The Black Cat. Kemunculan makhluk di sebuah rumah kosong, misalnya, dapat menimbulkan kesan misterius sekaligus menimbulkan suasana horor. Contoh lainnya adalah tokoh yang dirasuki oleh roh nenek moyangnya melakukan pembunuhan-pembunuhan, dan di akhir cerita perilaku tokoh itu dapat dijelaskan, misalnya, dengan menggunakan sudut pandang psikoanalisis. Perilaku Freddy Kruger dalam Nightmare on Elm Street yang melakukan teror dan pembunuhan dapat ditarik ke fenomena schizofrenia yang

\footnotetext{
7 Pendapat ini dikutip oleh Dominic Strinati dari T.Todorov. (1973). The Fantastic: A Structural Approach to A Literary Concept, Cleveland and London: Case Western Reserve University Press.
} 
diidap oleh tokoh itu yang mengalami kekerasan di masa lalunya, seperti juga pada film Seven.

Film horor yang digolongkan dalam bentuk horor yang mengagumkan merupakan kebalikan dari tipe pertama. Dalam tipe marvelous, justru penonton/pembaca dihadapkan pada akhir cerita yang memaksa mereka percaya atau menerima bahwa memang ada dunia yang "tak terjelaskan" atau yang "supernatural". Keberadaan makhluk luar angkasa, misalnya, dipandang sebagai sebuah kenyataan yang mungkin. Persepsi ini mengarahkan pemikiran kita untuk mengeksplorasi dunia supernatural sebagai bagian dari kehidupan manusia. Batasan 'mengagumkan' dalam tipe kedua ini sebenarnya terletak pada penerimaan atas realitas lain karena adanya logika kemungkinan. Hal itu dimungkinkan karena walaupun monster itu berada dalam dunia ketidakmungkinan (misalnya ada makhluk yang harus selalu meminum darah dan hanya bisa mati jika jantungnya ditembus kayu), tetapi hal itu dapat diterima sebagai kemungkinan (hal yang normal). Film-film horor yang menampilkan zombie, vampire, manusia serigala, atau adanya pemindahan jiwa dari satu tubuh ke tubuh lain adalah bentuk horor yang mengagumkan. Untuk bentuk horor seperti ini kita dapat menunjuk beberapa film, antara lain Zombie, The Omen, The Exorcist, Werezoolf, Dracula, dan The Vampire.

Bentuk horor yang digolongkan ke dalam bentuk horor yang luar biasa adalah sejumlah cerita (film) yang mengarahkan pembaca (penonton) ke situasi ragu-ragu, yaitu meragukan tentang hal-hal yang natural dan supernatural atau hal-hal yang nyata dan tidak nyata dalam kehidupan manusia. Penonton dibiarkan untuk mengembangkan pikirannya sendiri saat menyaksikan film horor itu, sehingga memunculkan keragu-raguan yang hebat. Keraguan itu timbul sejalan dengan pemikiran-pemikiran yang berkembang di masyarakat tentang sejumlah fenomena yang diyakini terjadi tetapi sukar untuk membuktikannya. Sebuah contoh untuk bentuk horor ini kita dapatkan pada film The X-Files yang di dalamnya kita sering disuguhkan (di akhir film) pada gambaran tokoh antagonis yang dipercaya mempunyai kelainan jiwa atau dirasuki oleh kekuatan supernatural (atau makhluk luar angkasa). Ketidakjelasan identitas dan karakter tokoh ini (di akhir cerita) menjadi faktor yang mampu menimbulkan banyak pikiran pada pembaca (penonton) dan hal itu dianggap oleh Todorov sebagai hal yang luar biasa dari film horor. Kekuatan supernatural dalam The Omen atau The Exorcist, misalnya, mengarahkan pikiran penonton untuk memahami hal-hal yang luar biasa dalam kehidupan manusia, khususnya tentang kekuatan-kekuatan gaib yang ada di luar dunia manusia dan masuk ke dalam kehidupan manusia.

\section{Horor Versi Hollywood}

Kehadiran cerita horor sudah ada sejak abad 19 melalui cerita Frankenstein dan Dracula. Kedua cerita itu sama-sama menampilkan makhluk yang menakutkan, kendati keduanya mempunyai asal-usul yang berbeda. Konsep horor dalam kedua cerita itu adalah menyajikan makhluk ganjil yang 
berwajah seram (Frankenstein) sebagai monster yang menakutkan. Eksploitasi wujud fisik yang seram mampu menimbulkan rasa takut. Kekerasan yang dilakukan oleh Frankenstein itu sendiri merupakan cerminan kekecewaannya pada si penciptanya. Hal serupa terjadi pada cerita Dracula yang mengeksploitasi wujud fisik dan kebiasaan kelelawar yang menghisap darah. Kemiripan perilaku dan transformasi fisik dari manusia menjadi kelelawar dan sebaliknya dijadikan modal awal untuk meneror pembaca (penonton). Modal awal ini kemudian diwujudkan dalam alur cerita yang dijalin sedemikian rupa sehingga mampu menghasilkan suasana horor. Namun demikian, dari perjalanan waktu, apa yang menakutkan untuk penonton pada 50 tahun lalu atau 10 tahun lalu tidaklah sama. Hal itu disebabkan adanya perubahan konsep horor itu sendiri yang muncul bersamaan dengan semakin beragamnya jenis film atau cerita horor.

Konsep awal cerita horor ini, seperti yang telah dikemukakan di atas, bersumber pada tradisi gotik Inggris yang berakar pada kesusastraan Inggris abad ke-18. Frankenstein bersumber pada obsesi manusia untuk menemukan hal-hal baru dalam bidang ilmu pengetahuan dan Dracula bersumber pada mitos Pangeran Dracula dari Skandinavia. Konsep horor yang dimunculkan dalam kedua cerita itu berkaitan dengan hadirnya "monster" yang mengancam keselamatan masyarakat. Jalinan cerita yang disusun sedemikian rupa mempunyai andil dalam menimbulkan kengerian dan ketakutan. Hal itu semakin menjadi-jadi ketika secara visual "monstermonster" itu tampil di hadapan penonton.

Perubahan besar-besaran pada konsep horor terjadi ketika cerita-cerita horor diangkat dari novel ke bentuk visual (film) sebagai hiburan. Berubahnya media penceritaan ini menyebabkan terbukanya eksplorasi konsep horor dalam bentuk visual-kendati pada awalnya film-film horor dibuat tanpa suara-yang memberi pengalaman secara "langsung" dalam menyaksikan wujud fisik dan berbagai tindakan seram lainnya. Aspek visual (dan kemudian audio) dalam film horor menempatkan film horor sebagai sebuah genre baru dalam dunia perfilman di Amerika, khususnya di Hollywood. Sukses yang diterima oleh film horor bisu Nosferatu (1930) yang dibuat di Jerman membuka mata Hollywood untuk memproduksi Dracula (1930), kemudian Frankenstein (dibuat dengan bersuara). Sejak itu muncullah berbagai versi dari kedua produksi tersebut baik sebagai sebuah sekuel maupun film yang berdiri sendiri. Kedua cerita horor ini dapat digolongkan ke dalam horor klasik yang menginspirasi film-film horor berikutnya. Hal itu terbukti melalui munculnya sejumlah sekuel dari Frankenstein, seperti The Bride of Frankenstein, demikian juga dengan sekuel Dracula, seperti Dracula's Daughter.

Konsep horor yang mendasarkan pada cerita-cerita lama atau mitos mulai ditinggalkan dengan munculnya film-film horor yang menggarap tentang pembunuhan berantai (serial killers) dan teror penyakit, khususnya pada tahun 1950-an. Dua tema ini pada dasarnya mampu menimbulkan ketakutan penonton. Pada perkembangannya kemudian sajian horor 
beralih ke penggarapan masalah-masalah psikologis, seperti pada film Psycho (1960) yang didasari karya Alfred Hitchcock.

Selesai dengan tema-tema dunia kematian dan penyakit, konsep film horor bergerak ke tema-tema tentang kedatangan alien dari luar angkasa. Makhluk luar angkasa dipandang sebagai teror yang mengancam kehidupan manusia dan dunia. Fenomena penguasaan jagat raya oleh kekuatan luar angkasa menimbulkan ketakutan dan kengerian bagi umat manusia. Film-film yang bertema makhluk luar angkasa ini memunculkan jenis "horor" lainnya, yaitu film thriller ('film yang menegangkan').

Konsep Todorov ini memang baik dan terbukti kegunaan dalam menjelaskan mengapa film-film atau cerita-cerita tertentu masuk ke dalam kategori horor atau genre lain yang berhubungan. Terlihat juga memang kalau konsepnya itu juga menggambarkan tema, tampilan, dan mitos yang tipikal yang diasosiasikan sebagai horor, sebagaimana juga fiksi ilmiah dan thriller psikologis, seperti atau dalam versi lain dapat kita saksikan pada film Scream atau I Know What You Did Last Summer. Namun bagaimanapun, analisis keseluruhan yang dilakukan Todorov ini tidak menghubungkannya secara utuh pada perubahan-perubahan sejarah.

Pencarian bentuk-bentuk baru dari cerita/film horor pada dasarnya mempertimbangkan mengenai hal apa yang mampu menimbulkan ketakutan pada masyarakat pada suatu kurun waktu tertentu. Pada tahun 1970-an muncul sejumlah film horor yang menggarap dunia kematian yang meneror masyarakat, antara lain seperti yang terlihat pada film Zombie dan sejumlah film lainnya yang membangkitkan monster-monster dari dunia kematian. Pada film-film seperti ini, kita disuguhi wajah-wajah seram yang carut-marut atau bangkitnya roh-roh gentayangan di dunia manusia.

Film horor yang dikembangkan Hollywood pada umumnya berpola adanya sebuah tatanan sosial yang terganggu oleh monster yang biasanya (tidak selalu) bukan manusia. Monster ini lalu biasanya melakukan aksi pembunuhan atau perbuatan kekerasan lainnya. Ia mengancam masyarakat dengan cara membunuh orang melalui cara-cara yang tidak biasa dan cenderung melibatkan kuasa yang bersifat supernatural atau tidak terjelaskan/terpahami sebagaimana karakter monster tersebut. Biasanya pada akhir cerita, lewat ilmu pengetahuan atau dengan terlebih dahulu mempelajari modus operandinya para tokoh (protagonis) bisa mengalahkan sang monster, ia bisa dihadapi dan kemudian dibunuh. Karena monster ini berasal dari dunia supernatural, bukan tidak mungkin monster ini akan kembali lewat sekuel berikutnya. Contoh untuk hal ini adalah pada film Species atau The Omen. Bentuk lain yang berpengaruh dalam perfilman horor adalah gabungan horor dan fiksi ilmiah. Era ini ditandai dengan munculnya kembali film-film horor seperti Dracula, Frankenstein, dan Doctor Jekyll and Mister Hide.

Ditinjau dari segi sosiologis, film horor ini merupakan perwujudan, baik lansung maupun tidak langsung, dari pengingatan pada jalan agama atau keimanan. Obat mujarab untuk menghalau arwah atau makhluk penghisap darah adalah dengan keimanan dan simbol-simbol agama. Misi tersebut 
nampak sangat jelas dalam film horor, namun demikian sekarang ini ada perubahan orientasi dalam film-film horor, yaitu sekadar menakut-nakuti.

TABEL 1

TEMA FILM HOROR HOLLYWOOD DARI MASA KE MASA

\begin{tabular}{|l|l|}
\hline Tahun & Tematik \\
\hline 1930-an & Mitos \\
\hline 1950-an & Psikologis, makhluk luar angkasa \\
\hline 1960-an & $\begin{array}{l}\text { Psikologis, makhluk luar angkasa, pembunuhan berantai,makhluk } \\
\text { halus, mitos }\end{array}$ \\
\hline 1970-an & Psikologis, pembunuhan berantai, makhluk halus, dunia kematian \\
\hline 1980-an s.d .sekarang & $\begin{array}{l}\text { Psikologis, pembunuhan berantai, makhluk halus, dunia } \\
\text { kematian, makhluk luar angkasa, mitos/legenda lokal, mitos }\end{array}$ \\
\hline
\end{tabular}

\section{Horor di INDONESIA}

Dunia perfilman Indonesia dimulai pada tahun $1920-\mathrm{an}^{8}$ yang ditandai dengan munculnya film Loetoeng Kasaroeng yang dibuat oleh Java Film Coy. Pada awal perkembangannya, cerita-cerita yang diangkat ke film adalah cerita-cerita rakyat, kisah kehidupan rumah tangga yang diangkat dari novel, cerita bersambung atau kejadian sebenarnya, dan kisah-kisah kepahlawanan. Film-film yang dibuat pada awal pertumbuhan film di Indonesia, antara lain Si Pitung, Annie van Mendut, Nyai Dasima, Terpaksa Menikah, Boenga Roos dari Tjikembang, Melati van Agam.

Pembuatan film horor di Indonesia sebenarnya baru terjadi kira-kira dua dekade terakhir ini. Selama ini, orientasi pembuatan film Indonesia lebih ke arah film drama, film remaja, dan film komedi. Di pihak lain, genre horor tidak banyak yang menggarap. Namun, akhir-akhir ini cerita-cerita menyeramkan dan misteri banyak dibuat dalam format sinetron (bukan layar lebar). Kehadiran sinetron-sinetron bertema misteri ini dapat digolongkan pada film horor. Sebuah film horor yang populer di Indonesia adalah Si Manis Jembatan Ancol. Film ini didasari oleh cerita yang beredar di masyarakat Ancol (Jakarta) tentang hantu yang kerap muncul di sekitar Jembatan Ancol.

Secara umum, konsep film horor di Indonesia tidak berbeda dengan konsep film horor yang dibuat di Hollywood. Kalaupun ada perbedaan, hal itu semata pada cara pengemasannya saja. Mengikuti batasan tipe horor yang telah dikemukakan Todorov, maka kecenderungan film horor di Indonesia digolongkan ke dalam tipe horor mengagumkan (the horrormarvelous). Tipe horor ini menunjukkan bahwa pada akhir cerita yang memaksa penonton percaya atau menerima bahwa memang ada dunia yang "tak-terjelaskan" atau yang "supernatural". Hal-hal yang bersifat

\footnotetext{
8 Pembuatan film cerita pertama kali di Indonesia dilakukan pada tahun 1926 (lihat Taufik Abdullah, H.Misbach Yusa Biran, S.M. Ardan, Film Indonesia Bagian I (1900-1950), Jakarta: Dewan Film Nasional (1993).
} 
supernatural, dunia gaib, cenderung paling banyak digarap untuk film horor Indonesia. Kecenderungan ini sangat erat kaitannya dengan pola pikir dan kepercayaan masyarakat Indonesia pada hal-hal yang gaib. Mitos Nyai Roro Kidul, misalnya, sudah sejak lama dipandang sebagai tokoh yang "nyata" dalam alam pikiran manusia Indonesia, khususnya masyarakat yang tinggal di sepanjang pantai selatan pulau Jawa. Mitos tersebut menjadi komoditas yang laku untuk dijual dalam dunia pertunjukan, termasuk film. Banyak sudah sekuel film dari cerita Nyai Roro Kidul ini, antara lain Nyai Roro Kidul dan Pembalasan Ratu Pantai Selatan. Selain soal mitos, yang banyak digarap untuk film horor juga arwah gentayangan (hantu). Film horor Indonesia tidak menyuguhkan monster atau yang horor bertema psikologis. Dengan kata lain, eksplorasi horor di Indonesia masih sangat terbatas dan tidak ada keragaman seperti di Hollywood.

Dari segi misi di balik film horor Indonesia, nampaknya ada kesamaan dengan misi film horor di Amerika atau Eropa, yaitu adanya jalan keluar untuk menghentikan gangguan arwah gentayangan (hantu) adalah dengan keimanan (agama). Sebaliknya, dalam film-film horor yang berdasarkan mitos Nyai Roro Kidul, misalnya, ditegaskan bahwa tokoh Nyai Roro Kidul diposisikan sebagai katalisator atau yang mampu menyelesaikan persoalan yang sedang dihadapi. Hal itu dapat dipandang adanya legitimasi atas tokoh dan mitos tersebut.

TABEL 2

TEMA FILM HOROR DI INDONESIA DARI MASA KE MASA

\begin{tabular}{|l|l|}
\hline Tahun & Tematik \\
\hline 1970-an & Makhluk halus, mitos lokal \\
\hline 1980-an & Mitos lokal \\
\hline 1990-an & Kisah misteri, arwah penasaran, mitos lokal \\
\hline
\end{tabular}

Fenomena maraknya tayangan-tayangan horor di televisi kita dengan berbagai temanya sekarang ini memperlihatkan suatu kontras dengan tayangan film horor dahulu yang lebih menunjukkan bahwa soal arwah dan sebagainya itu bisa dikalahkan dengan yang namanya iman/agama. Misi tayangan-tayangan horor sekarang ini sudah beda. Sekarang tampak kecenderungannya lebih ke arah, menakut-nakuti. Apalagi tayangan soal kisah nyata yang seram-seram, isinya murni membuat penonton takut dan secara serta merta percaya bahwa arwah gentayangan itu memang ada dan nyata. Hal ini sejalan dengan pendapat Todorov mengenai tipe marvelous tersebut karena elemen-elemen pendukungnya mengarahkan penonton untuk percaya kalau kejadian-kejadian yang ditayangkan itu benar dan bisa dipercaya.

Masih banyak hal yang perlu dijelaskan melalui penelitian lain berhubungan dengan masalah horor ini. Sejumlah hal dapat dikemukakan di sini, antara lain bagaimana hubungan timbal baliknya antara maraknya tayangan sejenis ini dengan kondisi sosial ekonomi masyarakat kita. Faktor 
mana yang memicu fenomena yang mana? Apakah industri sinetron/ televisi yang menggiring masyarakat untuk percaya hal-hal yang berbau supernatural atau sebaliknya, industri sinetron/televisi melihat fenomena yang berkembang ke arah itu, dan memanfaatkan situasi ini? Sejauh mana industri sinetron/televisi ini membentuk opini publik soal supernatural lewat tayangan-tayangan horor itu?

\section{KeSIMPULAN}

Berdasarkan uraian tentang film horor dapat disimpulkan beberapa hal berikut, yaitu sebagai berikut. Pertama, cerita horor yang kemudian berkembang di dunia perfilm dapat ditarik ke akarnya, yaitu bersumber dari zaman gotik, khususnya dalam kesusastraan Inggris. Kedua, definisi horor pada awalnya adalah cerita yang menyuguhkan ketidaknyamanan perasaan pada pembacanya, namun definisi ini terus berubah sejalan dengan perkembangan dunia perfilman. Dalam hal ini, film horor menjadi sebuah genre yang berdampingan dengan film drama, film komedi, film gangster, dan film laga. Ketiga, Sejumlah pemerhati film horor berusaha untuk memahami dan menjelaskan karakteristik film horor. Noel Carroll berusaha menjelaskan berbagai bentuk film horor; Todorov menjelaskan tiga tipe film horor berdasarkan akhir cerita, yaitu the horror-uncanny; the horror-marveluos; the horror-fantastic. Keempat, terdapat perbedaan mendasar cerita horor yang digarap di Hollywood dan di Indonesia. Penggarapan horor di Hollywood sangat beragam dan ditunjang oleh industri perfilman yang sudah mapan; sebaliknya keragaman cerita horor di Indonesia tidak ada. Hal itu terlihat dari sumber cerita horor yang terbatas. Kelima, pada perkembangannya kemudian antara horor, thriller, dan fiksi ilmiah tidak dapat dibedakan lagi batasan-batasannya. Keenam, kecenderungan tematik dalam film horor versi Hollywood dari waktu ke waktu berubah sesuai dengan minat penonton. Ketujuh, kecenderungan tematik dalam film horor versi Indonesia berkisar pada hal-hal gaib atau misteri.

\section{DafTAR ACUAN}

Abdullah, Taufik., Yusa Biran, H.Misbach., Ardan, S.M. (1993), Film Indonesia Bagian I (1900 1950). Jakarta: Dewan Film Nasional.

Carroll, Noel (1990), The Philosophy of Horror or Paradoxes of the Heart. New York: Routledge. Kayam, Umar (1981), "Film sebagai Sarana Hiburan dan Ekspresi Dramatik", dalam Seni Tradisi Masyarakat.

Lull, James (ed.) (2001), Culture in The Communication Age. New York: Routledge.

Shaw, Daniel (1997), "A Humean Definition of Horror", dalam "Film Philosophy", Vol.1 No.4, August 1997. <http://www.film-philosophy.com/vol1-1997/n4shaw>.

Strinati, Dominic (2000), An Introduction to Studying Popular Culture. London and New York: Routledge.

Todorov (1973), The Fantastic: A Structural approach to a literary concept. Cleveland and London: Case Western Reserve University Press.

Vanneman, Alan (2002), "Alfred Hitchcock and Psycho", dalam "Bright Lights Film Journal", <http://www.brightlightsfilm.com/28/psycho1.htm>. 